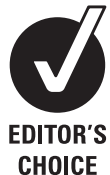

Pathology Department of San Cecilio University Hospital, Granada, Spain

\section{Correspondence to} Professor Francisco F Nogales, Depto Anatomia Patologica, Facultad de Medicina, Universidad de Granada, Hospital Universitario San Cecilio, Av Madrid 11, 18012 Granada, Spain:

fnogales@ugr.es

Accepted 12 November 2010 Published Online First

1 December 2010

\title{
Endometrial metaplasias and reactive changes: a spectrum of altered differentiation
}

\author{
Alina Nicolae, Ovidiu Preda, Francisco F Nogales
}

\section{ABSTRACT}

Endometrial metaplasias and changes (EMCs) are conditions frequently overlooked and misdiagnosed. The aim of this review is to update current issues and provide a classification with a practical clinicopathological approach. Hormonal or irritative stimuli are the main inducing factors of EMCs, although some metaplasias have a mutational origin. EMCs vary from reactive, degenerative lesions to those able to associate with malignancy or those having a preneoplastic potential. The most common types of EMCs are ciliated tubal metaplasia (CTM) and mucinous metaplasia (MM), which occur in simple and complex glands, and possibly these architectural changes hold the same prognostic significance as they do in hyperplastic endometrioid lesions. Immunohistochemically, CTM is positive for LhS28, bcl-2, PAX2 and p16 INK4A Complex CTM is likely to be a precursor of ciliated endometrioid-type carcinomas. MMs should be evaluated architecturally, taking into account that their atypicality is minimal. The differentiation between complex MM and mucinous carcinoma may be extremely difficult. Surface complex, papillary MM in endometrial polyps can be considered as benign. Intestinal-type endometrial MM is rare and its presence should prompt further investigation of associated lesions in the endocervix. Endometrial squamous metaplasia (ESS) is often linked to chronic irritative situations. It should be differentiated from secondary involvement by a human papilomavirus-related cervical lesion. Morular metaplasia is a mutational phenomenon with a distinct phenotype that helps to differentiate it from ESS. Morules are benign, hormonally inert structures that are often markers of complex endometrioid glandular architecture, and they are associated with an attenuated malignancy. Endometrial reactive changes are commonly associated with desquamation or hormonal imbalance. The frequent, p16 ${ }^{\text {NK } 4 A}$ positive, benign surface papillary syncytial change may be misdiagnosed, in some cases, as surface serous adenocarcinoma. Eosinophilic, oxyphilic, oncocytic and clear cell changes are non-specific. Rare stromal metaplasias have little clinical significance and should be differentiated from implanted fetal or embryonal tissues.

\section{INTRODUCTION}

Endometrial pathology is an important part of the daily routine in histopathology. As a result of its wide morphological variation, the diagnostic interpretation of endometria remains one of the least reproducible fields in gynaecological pathology. In the past, ${ }^{1}$ little attention has been paid to endometrial metaplasias and changes (EMCs), and thus they are conditions that are frequently overlooked and misdiagnosed. In this review we analyse the current information on this subject and attempt to provide guidelines for their interpretation and classification that are clinically relevant.

EMCs comprise a morphologically heterogeneous group of proliferations and differentiations found in eutopic and ectopic endometria. Their epithelial or mesenchymal components are replaced either by excessive quantities of homologous cells or partly by heterologous elements. Epithelial EMCs are the most frequent, while mesenchymal EMCs uncommonly occur. The former may occur, mostly focally, in surface and glandular epithelium, but in rare cases they can involve the whole endometrial cavity. While some are usually associated with physiological conditions such as menstruation or pregnancy, most occur in conjunction with pathological situations such as polyps, hyperplasia and adenocarcinoma. EMCs are rarely pure and often various histological types can be seen overlapping in the same specimen.

The tissues derived from the Müllerian ducts and those corresponding to the 'secondary Müllerian system $^{2}$ have a remarkable capacity to undergo multiple differentiations into almost any type of epithelium as well as into various mesenchymal tissues. The endometrium has one of the highest turnovers of cells, only matched by the intestinal lining. From the newborn to late menopause, the endometrium never becomes afunctional, only inactive, and always responds to hormonal stimuli. The continuous endometrial growth, maturation and shedding, performed in short periods of time, involve a myriad of cell cycles and consequently there are multiple opportunities for genetic changes.

\section{Origin}

It is likely that endometrial renewal is accomplished by stem cells. Although their identification has not yet been established, various putative candidates have been proposed. These include clonogenic endometrial cells, ${ }^{3}$ CD $146^{+}$PDGFR $\beta^{+4}$ or $\mathrm{CD} 29^{+} \mathrm{CD} 73^{+} \mathrm{CD} 90^{+}$stromal cells ${ }^{5}$ and endometrial side population cells. ${ }^{6}$ The latter are likely to be responsible for endometrial regeneration and perhaps originate from bone marrow stromal cells. ${ }^{7}$ They mainly reside in the vascular endothelial walls and perivascular areas of the basal and functional layers. $^{8}$

\section{Terminology}

Metaplasias are adaptive phenomena involving a newly acquired morphology and function. The term change does not necessarily involve true cell transformation, but rather a reactive response of the nucleus or cytoplasm. Neometaplasia, a poorly defined term, usually refers to unusual 
differentiations in tumours that reflect their heterogeneity and multipotency. In this review, we will analyse endometrial metaplasias of epithelium and stroma, as well as some frequent reactive epithelial cellular changes.

A proposal of classification for these lesions is presented in table 1.

\section{Associated phenomena and pathogenesis}

EMCs are observed in a variety of non-neoplastic and neoplastic conditions in all ages. EMCs and hyperplasia are not mutually exclusive lesions and they often coexist and overlap, since both are related to unopposed oestrogen stimuli. ${ }^{9}$ Furthermore, EMCs have also been described in endometria of patients with progesterone-coated intrauterine devices, ${ }^{10}$ and even associated with the new selective progesterone-receptor modulators. ${ }^{11}$ As a rule, EMCs are frequently seen in endometrial polyps, endometriosis $^{1213}$ and in the benign epithelial component of some tumours such as adenosarcomas. ${ }^{14}$ Finally, they can occur in diverse conditions such as chronic inflammation, trauma and vitamin A deficiency. ${ }^{15} 16$

It is clear from the frequent association of EMCs with neoplasia ${ }^{17-20}$ that they share some common pathogenetic pathways. However, since EMCs are such a highly heterogeneous group of lesions with different pathogeneses, it would be difficult to attribute them with a generical malignant potential. Although most EMCs are hormonally related and benign, some, such as morules, have a mutational origin and are mostly associated with glandular complexity and atypia. ${ }^{21-23}$ The malignant potential of reactive changes and stromal metaplasias is likely to be negligible.

Table 2 summarises the potential risk and association with malignancy of the different types of endometrial metaplasia and changes.

\section{EPITHELIAL EMIS}

Mucinous and tubal metaplasias are frequently admixed and are perhaps the lesions that cause the most problems of interpretation. They may occur in simple and complex glands, and their architectural changes possibly have the same prognostic significance as they do in endometrioid, hyperplastic lesions. Consequently, endometrial lesions with complex architecture are not restricted only to endometrioid-type glands, but may also involve mucinous or tubal glands.

\section{Endometrial ciliated and tubal metaplasia}

Ciliation is a characteristic feature of Müllerian epithelia, and its ubiquitous presence in the cervix, isthmus and normal

Table 1 Classification of endometrial metaplasias and changes

\begin{tabular}{ll}
\hline Endometrial metaplasias and changes \\
\hline Epithelial & Ciliary, tubal (simple and complex) \\
& Mucinous (simple and complex) \\
& - Intestinal variant \\
& Squamous \\
& Morules \\
& Reactive changes \\
& - Surface, papillary syncytial change \\
& - Onobnail variant \\
& - Clear cell, secretory \\
& Osseous \\
Cartilaginous \\
Adipose \\
Smooth muscle \\
- Myoid, sex-cord like \\
\hline
\end{tabular}

Table 2 Association of metaplasias and changes with neoplasia and malignant potential

\begin{tabular}{ll}
\hline $\begin{array}{l}\text { Type of endometrial metaplasia } \\
\text { and change }\end{array}$ & $\begin{array}{l}\text { Potential risk and association } \\
\text { with malignancy }\end{array}$ \\
\hline Morules & Nearly always \\
Ciliary, tubal complex & Frequent \\
Mucinous complex (including intestinal) & Frequent \\
Squamous & Rare \\
Surface, papillary syncytial change & Rare* \\
Oncocytic, oxyphilic, eosinophilic & Unknown \\
Clear cell, secretory & Never \\
Stromal metaplasia & Never $\dagger$
\end{tabular}

* May be present as reactive change in the surface of carcinomas during bleeding episodes. † May be present in the vicinity of carcinomas.

proliferative endometrium could suggest that lesions exhibiting a predominant ciliated component do not represent a true metaplasia but rather a hyperplasia of ciliated cells. Nevertheless, the term 'ciliated metaplasia' is used when the majority of cells of surface epithelium or endometrial glands are prominently replaced by ciliated cells (figure 1). The term 'tubal metaplasia' requires the presence of the three types of cell that constitute the tubal epithelium: ciliated, secretory and intercalary cells (figure 2). However, these differences are merely academic and are not particularly significant.

In the endometrium, ciliated and tubal metaplasia (CTM) is the most common type of metaplasia and also occurs frequently in the cervix, where its location at the squamocolumnar junction, mild atypicality, lack of intracytoplasmic mucin and frequent positivity for $\mathrm{p} 16^{\mathrm{INK} 4 \mathrm{~A}}$ can lead to its misdiagnosis as an in situ endocervical adenocarcinoma. ${ }^{24} 25$ In the uterine isthmic region, ciliated glands are so common as to be considered normal.

Endometrial CTM is mostly described in conjunction with unopposed oestrogen levels, ${ }^{1} 1726-29$ and its association with simple and complex endometrial hyperplasias ${ }^{9}$ and well-differentiated adenocarcinomas is striking. ${ }^{17-19} 29$ Residual CTMs can be found in atrophic endometria, where they remain unchanged even after radiotherapy. Endometrial polyps and adenosarcomata also have CTM as a common glandular component. ${ }^{14}$ Furthermore, endometriosis is a frequent site of tubal metaplasia ${ }^{12} 13$ and when it occurs in the ovary should be differentiated from benign serous neoplasms.

Simple CTM occurs in normal-size or cystic tubular glands and represents the most common type of benign EMC. However, complex CTM occurs in glands that have stellate or

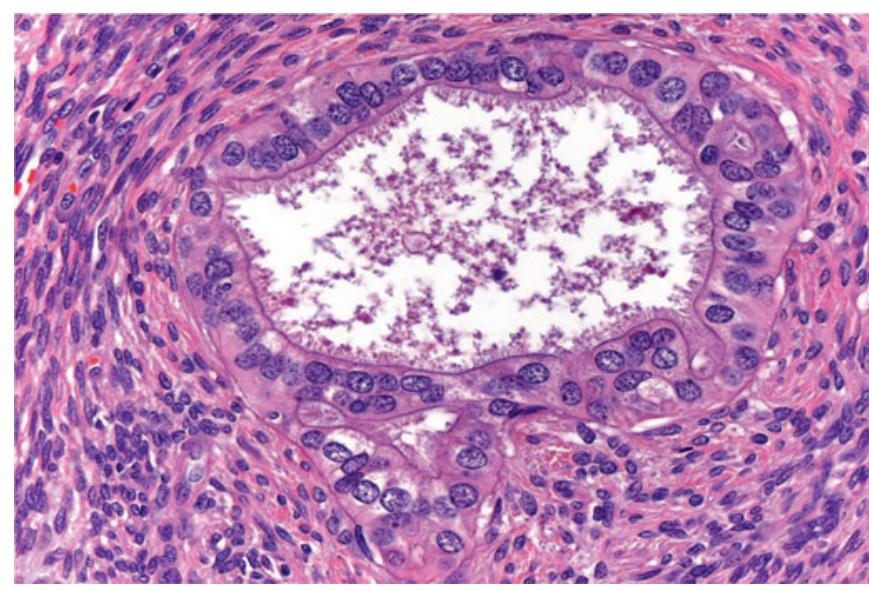

Figure 1 Isolated tubular gland lined by ciliary cells. 


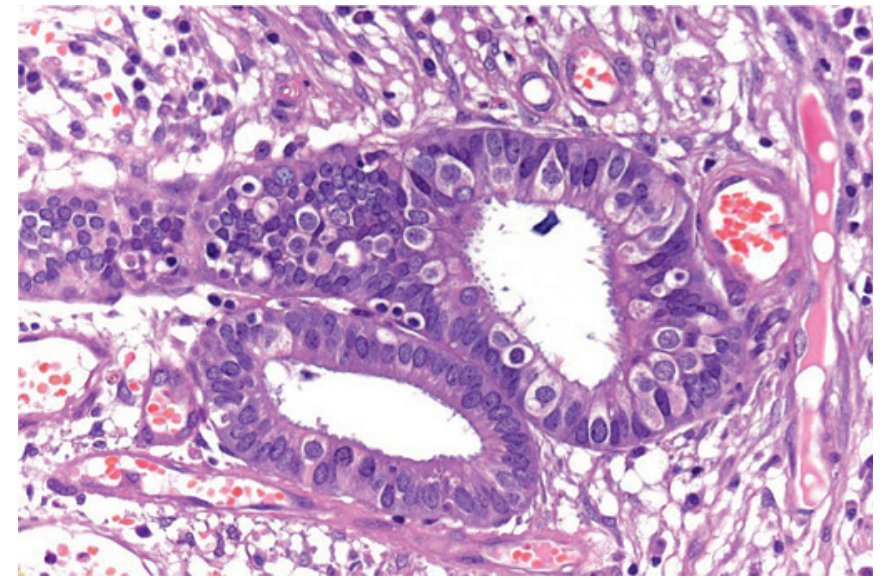

Figure 2 Tubal metaplastic glands showing secretory, ciliary and intercalary cells.

angular contours (figure 3), which are found together with complex changes such as papillae (figure 3) or stratification that may even display a cribriform appearance 1917182730 (figure 4). We believe that the main discriminating feature between lesions with and without malignant potential is architectural, since atypia is usually minimal, even in ciliated adenocarcinoma. This is evident in the closely related lesion of mucinous metaplasia, where architecturally complex glands, even with no atypia, often associate and merge with endometrioid adenocarcinoma. Consequently, complex CTM of the endometrium should be managed as a complex endometrial hyperplasia. ${ }^{30}$ However, when focal complex CTM is restricted to endometrial polyps it seems to have little relevance.

Although the CTM immunophenotype has been amply studied in the cervix, there are few immunohistochemical studies of endometrial CTM. LhS28, an antibody that reacts with basal body of cilia, helps to demonstrate ciliary differentiation, ${ }^{31}$ while $\mathrm{p} 16^{\text {INK4A }}$ is constantly positive usually in a mosaic or focal fashion ${ }^{32}$ (figure 5). CTMs have a low Ki67 index, and p53 shows a weak and heterogeneous pattern. ${ }^{28}$ Similar to findings in the fallopian tube epithelium, ${ }^{33}$ only the secretory cells of CTM are positive for bcl-2 (figure 6) and also for PAX2.

If complex CTM is likely to be a precursor of an endometrial carcinoma, which type of carcinoma does it precede? The likeliest

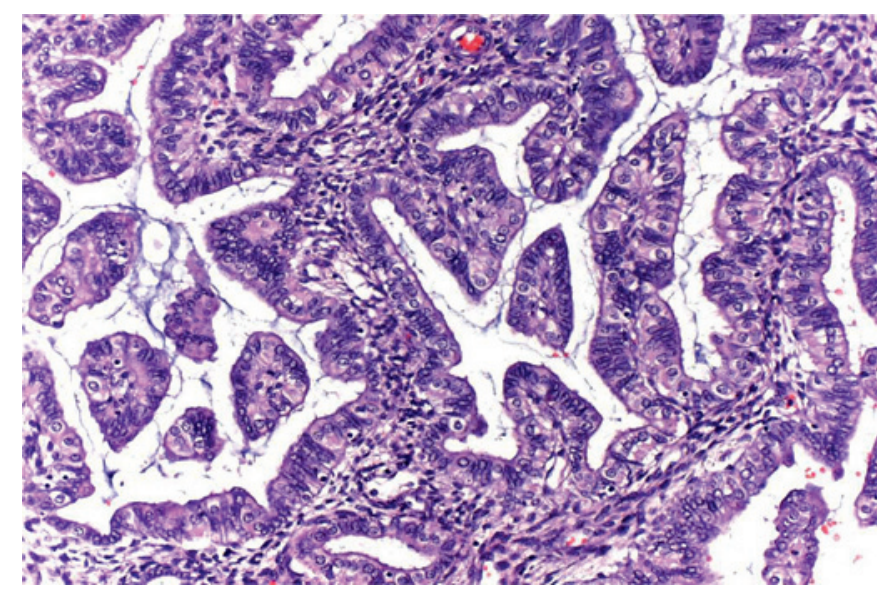

Figure 3 Complex stellate and papillary area of complex tubal metaplasia.

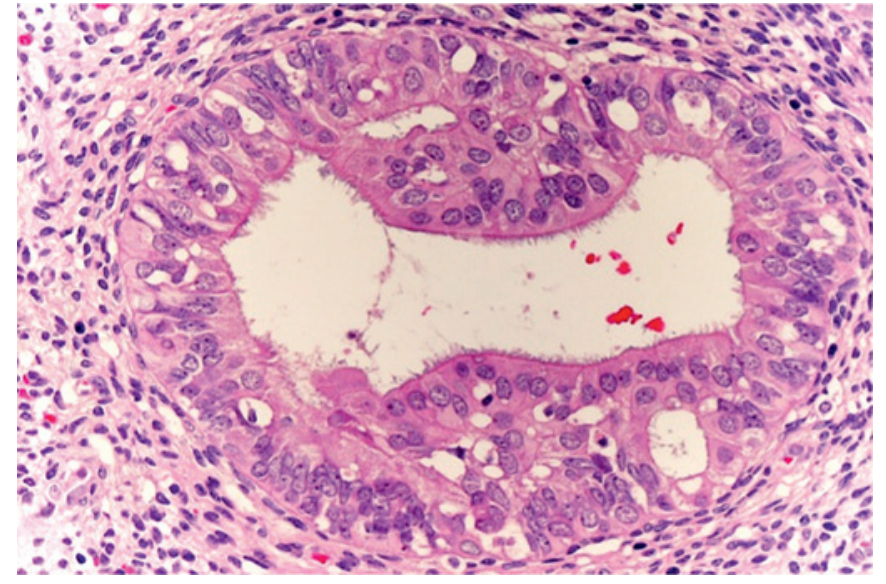

Figure 4 Complex, cribriform glands in tubal metaplasia.

candidate would be well-differentiated endometrioid carcinoma with extensive ciliary change. ${ }^{34}$ There is no contrasted clinicopathological evidence that tubal metaplasias ${ }^{32}$ represent precursor lesions of serous carcinoma.

We have been able to demonstrate PTEN and K-ras mutations and microsatellite instability in some cases of complex CTM that had a concurrent weak p53 expression (A Nicolae, personal communication). This profile would support CTM as a precursor of endometrioid but not of serous carcinoma.

Although presence of cilia is associated with a high grade of cellular differentiation, it must be borne in mind that some welldifferentiated endometrioid adenocarcinomas are of ciliated type. $^{27} 3435$ This diagnosis should be reserved only for cases with features of invasion, ${ }^{27}$ the exception being florid, cystic endosalpingiosis, which is a rare condition in which pseudoinvasive, benign glands with extensive CTM are found deep within the myometrium. $^{36}$

\section{Endometrial mucinous metaplasia}

Endometrial mucinous metaplasia (EMM) often occurs in perimenopausal and postmenopausal women, on the surface of atrophic senile endometria and in patients undergoing hormonal treatment, when it may be also accompanied by squamous or tubal metaplasia. ${ }^{137}$ EMM is frequent in tamoxifen polyps, ${ }^{38} 39$ the benign glandular component of adenofibromas and adenosarcomas, ${ }^{14}$ and in ovarian and pelvic endometriosis. ${ }^{12} 13$

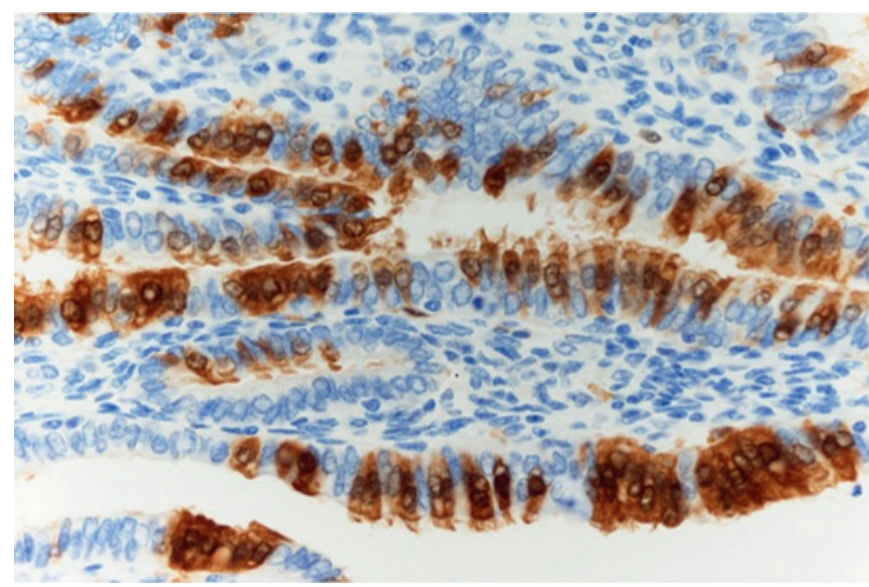

Figure 5 Mosaic p16 positivity in tubal metaplasia. 


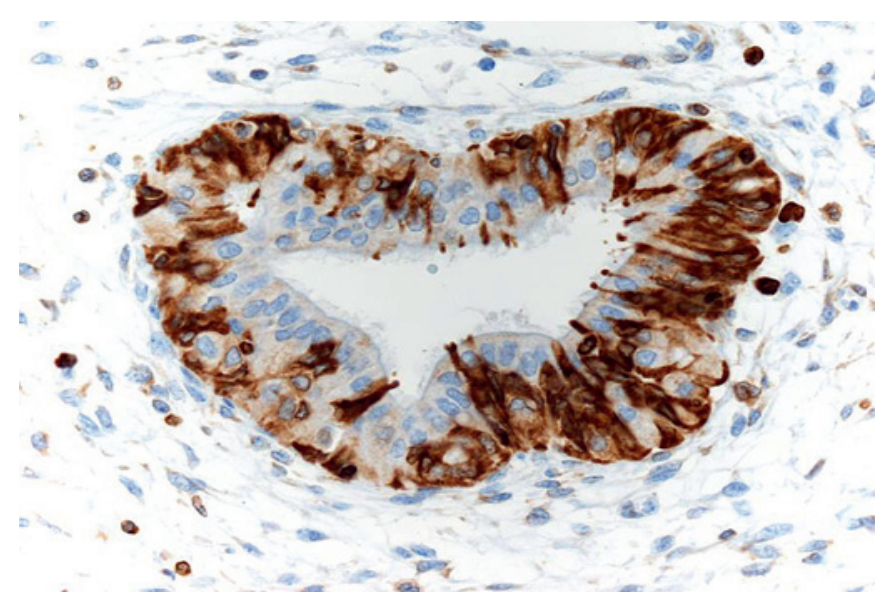

Figure 6 Positivity for bcl-2 in intercalary and secretory cells.

Mucinous metaplasia usually involves the endometrium focally rather than in a diffuse fashion. ${ }^{1}$ Rare, extensive EMM can lead to myxometra, an unusual condition defined as accumulation of mucus in the uterus. ${ }^{40}$ EMM can also occur as synchronous and multifocal lesions elsewhere in the female genital tract. ${ }^{41}$

In the same way as CTM, EMMs may arise as a response to hormonal stimuli. ${ }^{1}{ }^{37}$ Because of their frequent association with other types of metaplasia (tubal, eosinophilic, papillary change), EMM can be regarded as one of the multiple morphological aspects of the same process. ${ }^{37} 42$ EMM can occur as a reactive phenomenon when associated with cervical stenosis or cervical agenesis, ${ }^{40} 43$ suggesting a potential irritative role of fluid retention. Nevertheless, mucinous lesions may represent monoclonal alteration of the endometrium, ${ }^{44}$ and this would explain their relationship with neoplasia. This is clearly seen in STK-11 gene mutations, especially in patients with Peutz-Jeghers syndrome, ${ }^{45}$ where EMM occurs as a spectrum of histological changes ranging from metaplasia to carcinoma, involving synchronously cervix, corpus, fallopian tube and ovary. Multifocality, however, can also occur sporadically. ${ }^{41} 43$

In curettage material, interpretation of EMM can be difficult; indeed, a three-tier morphological classification of progressively architecturally complex lesions has been proposed. ${ }^{37}$ This approach, however, has been found to have little reproducibility $^{42}$ and, consequently, simplification is preferable. ${ }^{46} \mathrm{We}$ prefer interpreting EMMs into a two-category scheme using the terms simple and complex EMM.

Simple EMM represents the substitution of the endometrial lining of glands and surface epithelium by tall, bland, columnar mucinous cells of endocervical type (figure 7). It shares common histochemical and immunophenotypical properties with benign endocervical epithelium, such as expression of various mucin core proteins. $^{29} 47$

In complex EMM, the mucinous cells line architecturally crowded, irregular glands. Their columnar lining may present tufting, micropapillary or papillary infoldings (figure 8). More complex proliferations may have a microglandular or cribriform pattern similar to endocervical microglandular hyperplasia, even displaying clusters of neutrophils within intraepithelial microcystic structures. Budding or branching of the glands may also be present. The mucin-secreting cells can be intermixed with tubal-type cells and their nuclear atypia varies from absent to mild. Mitoses are rare. Complex EMMs may occur in association with complex endometrioid lesions (figure 9) and in the vicinity of, and often undistinguishable from, mucinous carcinomas.

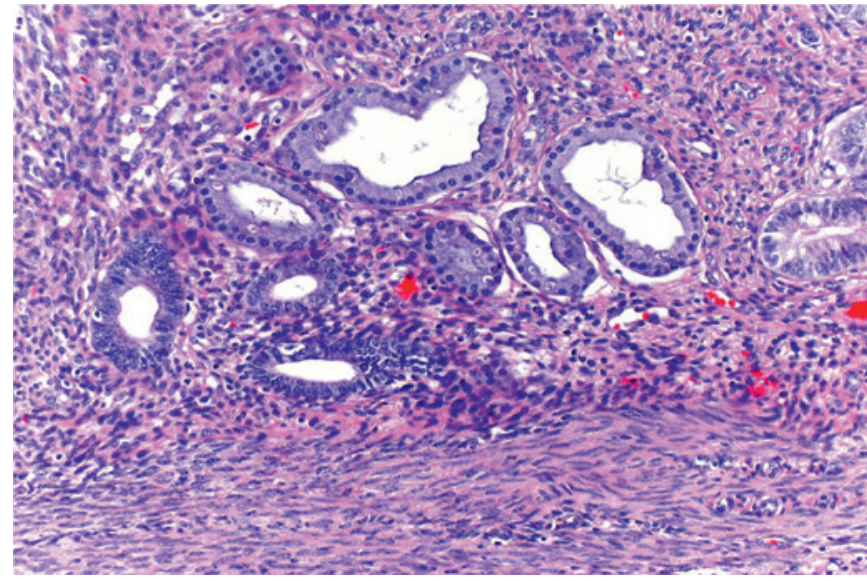

Figure 7 Simple mucinous metaplasia in the basalis of an atrophic endometrium.

Clinicopathologically, we consider simple EMM as benign lesions, while complex EMM should be managed in the same way as complex hyperplastic endometrioid glands, although bearing in mind that in EMM there is little (if any) atypicality. An exception would be cases of endometrial polyps with a surface EMM complex papillary proliferation; these are benign. ${ }^{48}$ Frequent misinterpretations of EMMs include microglandular endocervical hyperplasia ${ }^{49}$ and the rare microglandular variant of endometrioid carcinoma. ${ }^{50}$

In endometrial biopsy interpretation of complex mucinous lesions, it should be remembered that minimal atypia does not preclude a diagnosis of mucinous adenocarcinoma.

EMM rarely exhibit full intestinal type differentiation, which can occur in the endometrial surface and in polyps. ${ }^{51}$ This lesion is characterised by glands lined by columnar cells with a brush border, goblet cells and sometimes a variable number of neuroendocrine cells (figure 10). Similarly, their immunophenotype is characteristically intestinal with expression of villin, CK20, CDX2 and chromogranin. Intestinal metaplasia is commoner in the cervix where it is nearly always associated with in situ or invasive adenocarcinomas. For this reason, intestinal EMM should be managed with caution and any endocervical neoplastic lesions should be excluded.

\section{Endometrial squamous metaplasia}

In the Müllerian system, the incidence of squamous metaplasia increases caudally. While squamous metaplasia of the cervix is

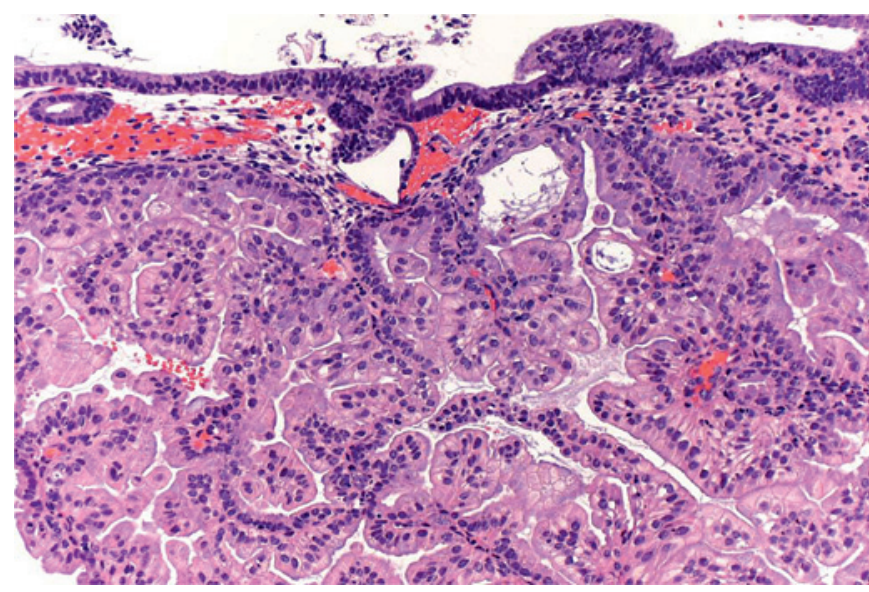

Figure 8 Complex papillary mucinous metaplasia in curettings. 


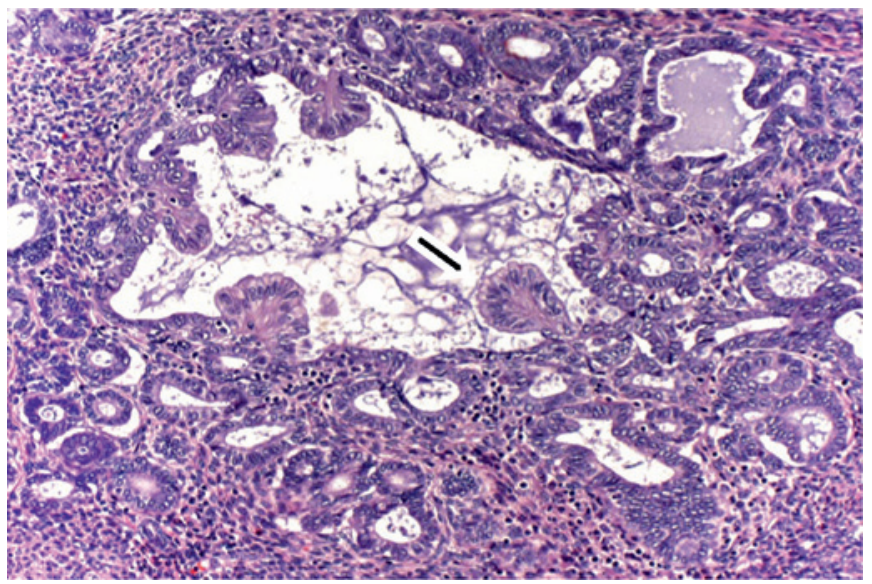

Figure 9 Complex endometrioid hyperplasia with a glandular space lined by micropapillary mucinous metaplasia (arrow).

common, it is rare in the non-neoplastic endometrium and exceptional in the fallopian tube. ${ }^{52}$

Endometrial squamous metaplasia (ESM) replaces the surface or endometrial glands with mature, non-keratinising, well-differentiated squamous cells. The term squamous metaplasia should be restricted to benign lesions, while the term squamous differentiation should be applied preferentially to carcinomas. ${ }^{53}{ }^{54} \mathrm{ESM}$ is usually a focal process but can be diffuse, involving extensive areas of the endometrial cavity, when it is known as ichthyosis uteri. $^{55}$

ESM may occur as a response to chronic irritative situations, such as cervical obstruction, chronic endometritis including tuberculosis, ${ }^{56}$ pyometra, ${ }^{57}$ and foreign bodies such as the earlier intrauterine devices. ${ }^{59}$ Various other situations including uterine artery embolisation of leiomyoma, ${ }^{60}$ vitamin A deficiency ${ }^{61}$ and even progestin therapy ${ }^{62}{ }^{63}$ have been reported as possible aetiopathogenetic factors of ESM.

The malignant potential of ESM is low, with only a few reports of isolated cases of pure squamous carcinoma developing from ichthyosis uteri. ${ }^{64}$ These should be differentiated from the endometrial involvement by cephalad extension of human papillomavirus-related squamous cervical lesions such as verrucous carcinoma, cervical condylomata and squamous intraepithelial neoplasia. ${ }^{65} 66$

ESM is frequently related to endometrioid carcinoma. It has been proposed ${ }^{67}$ that the finding of an extensive $(>2.1 \mathrm{~mm})$ solid

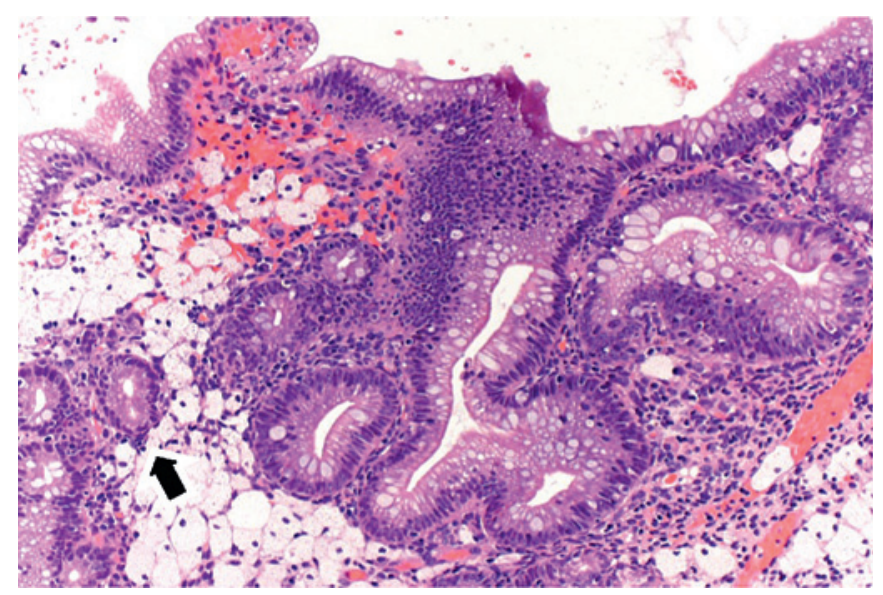

Figure 10 Complete intestinal metaplasia of endometrium. Isolated normal endometrial glands are present (arrow). squamous proliferation in a curettage specimen would imply a diagnosis of carcinoma, although this may be an exaggeration. ${ }^{68}$

The relationship of ESM with morules is interesting. Although ESM originates de novo from neoplastic glands, in a fifth of cases it coexists with morules (see below), where transitions between the distinct two types of metaplasia occur. ${ }^{1235358}$ This does not mean that neither all ESMs are necessarily neoplastic nor that all ESMs necessarily originate from morules.

\section{Morules}

Squamoid endometrial nodules and their morphological differences with ESM were reviewed as early as 1930 by Robert Mayer. ${ }^{69}$ The current term of morule, which refers to its morphological similarity with a mulberry, was subsequently coined in $1959 .^{70}$

Morules are rounded, well-circumscribed aggregations of uniform, oval or spindle-shaped cells with regular, inactive nuclei and an eosinophilic cytoplasm. They merge with ESM in 20\% of cases. Morules originate within the glandular epithelium, protrude and eventually plug the entire lumen, and this leads to epithelial atrophy, forming 'free' stromal nodules. Central necrosis of comedo type is more frequent in the larger morules, probably due to ischaemia. Optically clear nuclei are frequent. ${ }^{23} 54$

Although the occurrence of ESMs in normal endometria or polyps is $\operatorname{rare}^{23}$ (figure 11), they are nearly always associated with focal complex endometrial glandular lesions in the eutopic and the ectopic endometrial tissue. ${ }^{235358}$ Morular metaplasia is also seen in endometrial polyps with complex glands and in atypical polypoid adenomyoma, where they are considered a requisite for diagnosis. ${ }^{46}$ Rarely, morules are associated with chronic endometritis, submucosal leiomyoma, irradiation and intrauterine devices, ${ }^{53}$ but this is likely to be coincidental rather than a pathogenetical relation.

Does morular metaplasia represent an early step in squamous differentiation, or do they represent two distinct phenomena? Some authors consider them an immature stage of squamous differentiation. ${ }^{15758}$ Nevertheless, we believe they are separate entities based on their different biological potential, ${ }^{23}$ and their morphological $^{70}$ and immunohistochemical features. ${ }^{23} 53 \quad 54$ Table 3 highlights the main immunophenotypical differences between morules and ESM. From a practical viewpoint, positivity for diffuse and membranous CD10, nuclear CDX2 and $\beta$-catenin is constant in morules and usually differentiates them well from ESM. Empty, clear nuclei contain biotin ${ }^{23} 53547578$ and are identical with those present in pregnancy, where they

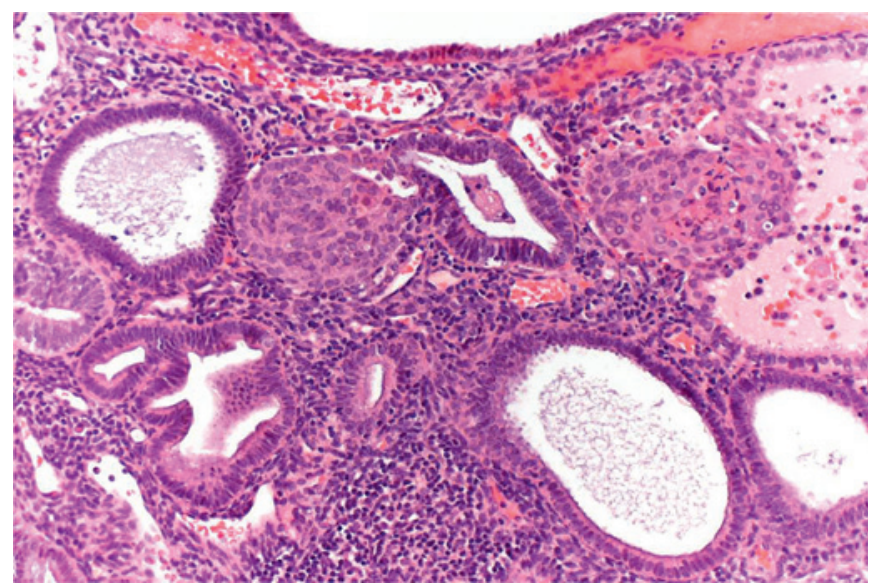

Figure 11 Morular metaplasia in a polyp associated with simple glands. 
Table 3 Immunohistochemical differences between morular and squamous metaplasia

\begin{tabular}{|c|c|c|}
\hline Marker & Morular & Squamous \\
\hline CD10 & Positive diffuse $e^{23} 5871$ & Negative $^{23} 71 /$ focal positive ${ }^{58}$ \\
\hline$\beta$-Catenin & $\begin{array}{l}\text { Positive diffuse, strong cytoplasmic and } \\
\text { nuclear positivity }{ }^{21-23} \quad 53 \quad 58 \text { 71-78 }\end{array}$ & $\begin{array}{l}\text { Positive (membrane)/rare positive } \\
\text { nuclei }^{21} 235358717477\end{array}$ \\
\hline $\operatorname{cDX} 2$ & Positive diffuse $\mathrm{e}^{58} 7677$ & $\begin{array}{l}\text { Negative/focal positive basal and } \\
\text { parabasal cells }{ }^{58} 77\end{array}$ \\
\hline $\mathrm{ER} \alpha, \mathrm{PR}$ & Negative/focal positive 2353587579 & Positive focal (most cases) ) $^{23} 5358$ \\
\hline p63 & Negative/focal peripheral positivity ${ }^{58}$ & Positive ${ }^{58}$ \\
\hline Involucrin & Negative $^{5354}$ & Positive ${ }^{5354}$ \\
\hline EMA & Negative $^{5354}$ & Positive 5354 \\
\hline Biotin & Positive 2353547578 & Negative $^{53}$ \\
\hline Neuroendocrine markers & Positive focal (some cases) ${ }^{5354}$ & Negative $^{5354}$ \\
\hline NSE & Positive ${ }^{5354}$ & Negative $^{5354}$ \\
\hline HPV DNA & Negative $^{53}$ & Positive (some cases) ${ }^{53}$ \\
\hline
\end{tabular}

EMA, epithelial membrane antigen; ER, oestrogen receptor; HPV, human papillomavirus; NSE, neuron-specific enolase;

$\mathrm{PR}$, progesterone receptor.

are related to steroid hormone hyperstimuli. ${ }^{78}$ The reactivity for various cytokeratins (not included in table 3) varies widely between studies. $^{23} 535458$

An interesting immunohistochemical feature of morular metaplasia is a neuroectodermal aberrant phenotype represented by the expression of neuron-specific enolase, synaptophysin, S-100, somatostatin and acethylcholinesterase. ${ }^{53}{ }^{54}$ We have seen cases of massive morular metaplasia in endometrioid lesions with chromogranin and synaptophysin positivity (figure 12) that prompted a differential diagnosis with neuroendocrine carcinoma.

Endometrial morules display identical histology and immunophenotype to those found in tumours of various sites such as gastrointestinal, lung and thyroid. They are highly specific in rare neoplasms such as low-grade adenocarcinoma of fetal lung type and the cribriform morular variant of papillary thyroid carcinoma. ${ }^{71}$ It has been proposed that tumours containing morules reflect a common pathway of carcinogenesis involving molecular alterations of the Wnt-signalling pathway with nuclear $\beta$-catenin accumulation. ${ }^{54} 71758081$ Also, all morules have in common nuclear expression of $\mathrm{CDX}^{58} 7677$ and $\beta$-oestrogen receptor, ${ }^{75}$ which appear to be related to their pathogenesis.

Morules are hormonally inert, with absence of $\alpha$-oestrogen and progesterone receptors 35558579 and a very low proliferative index. Consequently, they neither participate actively in the neoplastic transformation compared with their oestrogensensitive glandular counterpart nor are they influenced by progestative therapy. ${ }^{23} 79$ Thus, complex glandular lesions with morules will eventually result in adenocarcinoma but not in squamous carcinoma. ${ }^{79}$ The proportion of endometria with morular metaplasia that may progress into adenocarcinoma will be dependent strictly on the architecture and cytological atypia of the glandular component. In the rare cases, where there is absence of complex glandular changes, they are likely to have a benign outcome. In contrast, lesions associated with complex glandular proliferation, with or without atypia, can develop adenocarcinomas. ${ }^{30} 79$ These are usually well differentiated and have an attenuated malignancy. ${ }^{22} 235771758081$

Apart from the aforementioned differences with squamous metaplasia, morular changes can mimic granulomata, stromal or smooth muscle lesions, and may be indistinguishable from the spindle cell areas ${ }^{82}$ present in some endometrioid carcinomas.

In summary, although morules are a benign metaplastic differentiation, they are often markers of glandular complexity and attenuated malignancy. Their presence in apparently normal glands or in aspiration biopsies should prompt curettage in order to exclude complex glandular lesions. Their immunophenotype is complex and different from squamous metaplasia, which is a lesion into which they may differentiate. ${ }^{23}$ Biopathologically, they may reflect a special pathway of cancer development common to various organs, involving the $\beta$-catenin gene.

\section{Endometrial reactive changes}

Endometrial reactive changes comprise a heterogeneous group of lesions that can be associated, among others, with desquamation, hormonal imbalance, ischaemia and the vicinity of tumours.

Endometrial surface papillary syncytial change (SPSC) has been known under a host of terms such as papillary metaplasia, ${ }^{1}$ surface syncytial change, ${ }^{68}$ syncytial papillary hyperplasia, ${ }^{83}$ papillary syncytial change ${ }^{84}$ and eosinophilic syncytial change. ${ }^{85}$

SPSC is frequently associated with endometrial breakdown, occurring in normal conditions such as physiological, cyclic desquamation, and it is also present in abnormal endometrial conditions such as polyps, hyperplasias and even in biopsies of endometrioid adenocarcinoma taken during metrorrhagia. ${ }^{86}$

Microscopically, SPSCs are found as surface syncytial aggregates of eosinophilic cells occasionally extending into the subjacent glands. They often surround basophilic, stromal naked aggregates ('stromal balls') (figure 13). They frequently form micropapillae and even papillae containing fibrous cores. Sometimes, moderate to marked nuclear irregularity and occasional mitoses can be present. Neutrophils are often incorporated into the eosinophilic epithelium. Changes usually associated with endometrial breakdown such as haemorrhage, stromal balls, acute inflammation and fibrin thrombi are almost invariably associated.

The significance of SPSC is yet unknown. Two main pathogenetic possibilities have been considered. Some ${ }^{87} 88$ favour the possibility of a cellular change associated with endometrial regeneration, while others ${ }^{84} 85$ interpret it as a degenerative phenomenon secondary to the ischaemia that occurs during endometrial shedding. Its strong cytoplasmic and nuclear p16 $6^{\text {INK4A }}$ positivity ${ }^{89}$ (figure 14) would support the latter. Others have considered it as a metaplastic ${ }^{1}$ or hyperplastic ${ }^{83}$ phenomenon.

SPSC may reveal atypical cellular and architectural features that may be misinterpreted as malignant. Its main differential diagnosis is with papillary serous carcinoma, as this highly aggressive tumour is also a surface lesion in its early stages; however, it is much more commonly found in the atrophic 


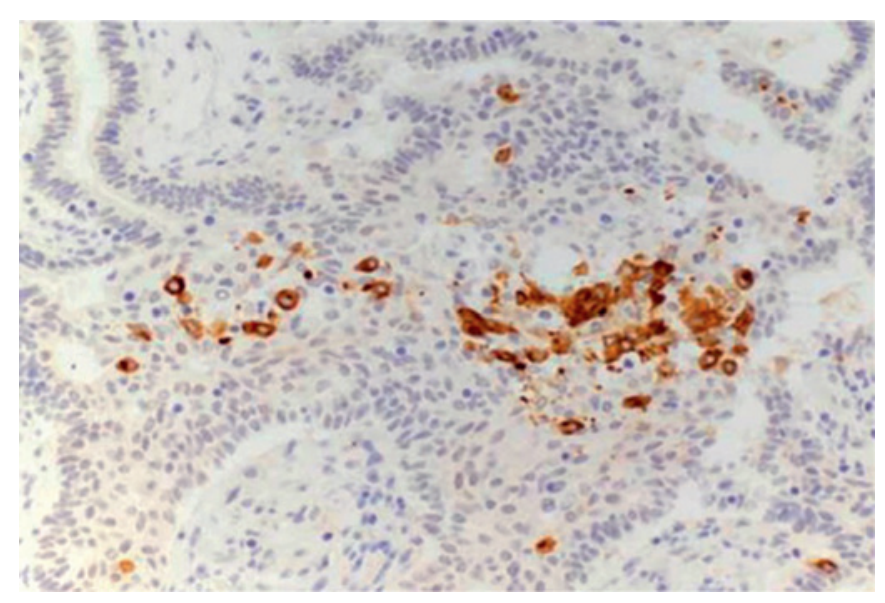

Figure 12 Synaptophysin positivity in morules. Other neuroendocrine markers were also expressed.

endometrium of older patients and only rarely in the premenopausal menstrual mucosa. Although SPSC and serous carcinoma can be p53 positive, their staining pattern is different, being heterogeneous and weak in SPSC, and strong and diffuse in serous carcinoma and its precursors. Furthermore, the Ki67 index is high in serous carcinoma and very low or absent in SPSC. $^{28}$

\section{Hobnail change}

This change often appears as a reactive phenomenon after curettage or abnormal bleeding, and is a type of SPSC. Histologically, the surface and/or glandular epithelia are replaced by teardrop-shaped cells with an appearance reminiscent of the Arias-Stella phenomenon, clear cell carcinoma or the detached eosinophilic cells of a serous adenocarcinoma. They have scanty eosinophilic or clear cytoplasm and prominent apical nuclei that bulge into the luminal spaces. Hobnail change can also be associated with radiotherapy. In gestational and puerperal endometria hobnail change represents an Arias-Stella phenomenon. Similarly, it can be found in Mirena coil endometria. ${ }^{10}$

\section{Oxyphilic, oncocytic and eosinophilic changes}

All these terminologies have the non-specific histological features of eosinophilia as their common denominator. These changes can be considered as reactive alterations rather than true

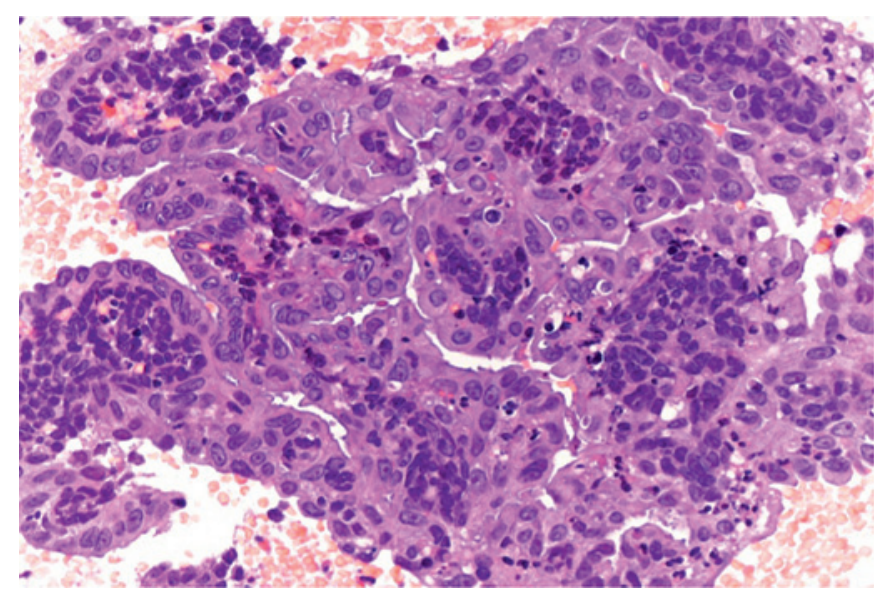

Figure 13 Surface papillary syncytial change enveloping collapsed stromal balls.

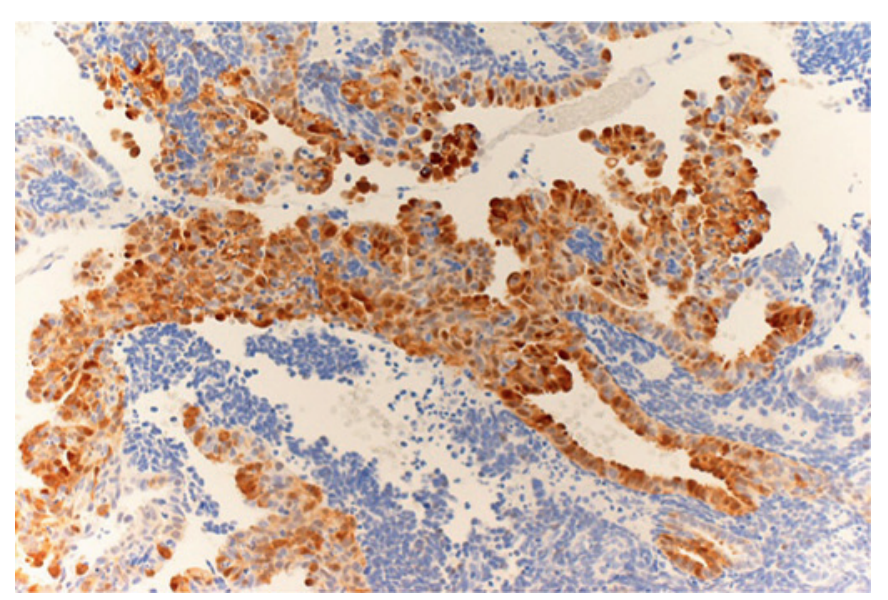

Figure 14 Positivity for p16 highlights surface papillary syncytial change areas.

metaplasias. They can occur in a host of normal, non-neoplastic and neoplastic endometria ${ }^{1} 195790$ where they may be associated with other types of epithelial metaplasias and changes, especially with SPSC and CTM. Among them, oncocytic cytoplasmic changes are the most unusual (figure 15) and can present with nuclear atypia, which is not necessarily a criterion for malignancy, since they may only represent degenerative phenomena. ${ }^{68}$ Oxyphilic or oncocytic changes can involve architecturally complex glands and even adenocarcinomas of the eutopic $^{3090-92}$ and ectopic endometrium. ${ }^{1293}$

The nature of these eosinophilic cells is poorly understood, being considered by some as a form of immature mucinous metaplasia, ${ }^{29} 94$ while for others, they represent a surface degenerative change. ${ }^{85}$ This is supported by their presence in the vicinity of endometrial granulomatous lesions. ${ }^{56} 95$

The importance of recognising eosinophilic metaplasia resides in distinguishing it from oxyphilic or oncocytic adenocarcinoma, especially when the latter shows only minimal cytological atypia. ${ }^{90} 92$ Hepatoid areas associated with endometrioid carcinomas may also have oncocytic-type changes. ${ }^{96}$

Clear cell or secretory change

The finding of secretory glands with vacuolated or apocrine-like cells in an endometrium with proliferative features points to a hormonal imbalance (spontaneous or iatrogenic) rather than to

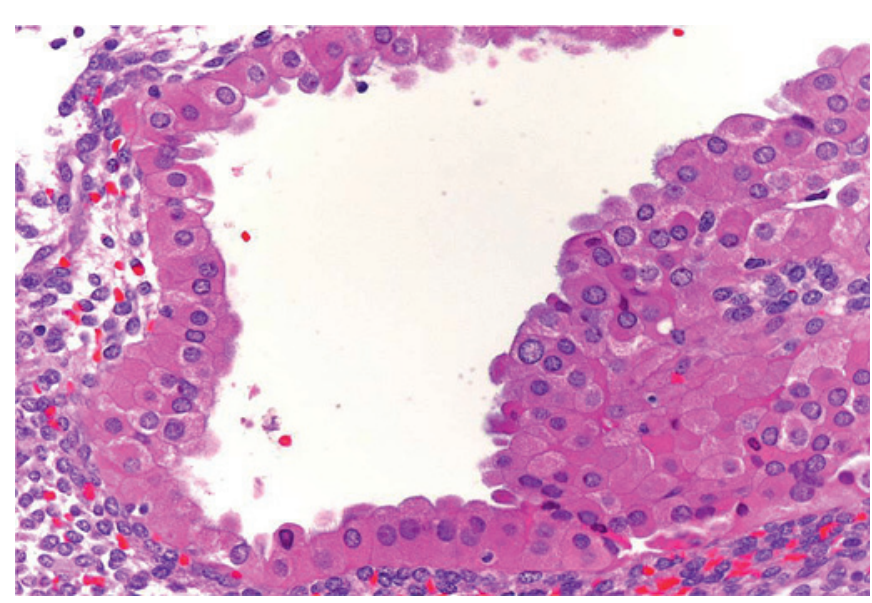

Figure 15 Oncocytic metaplasia. 


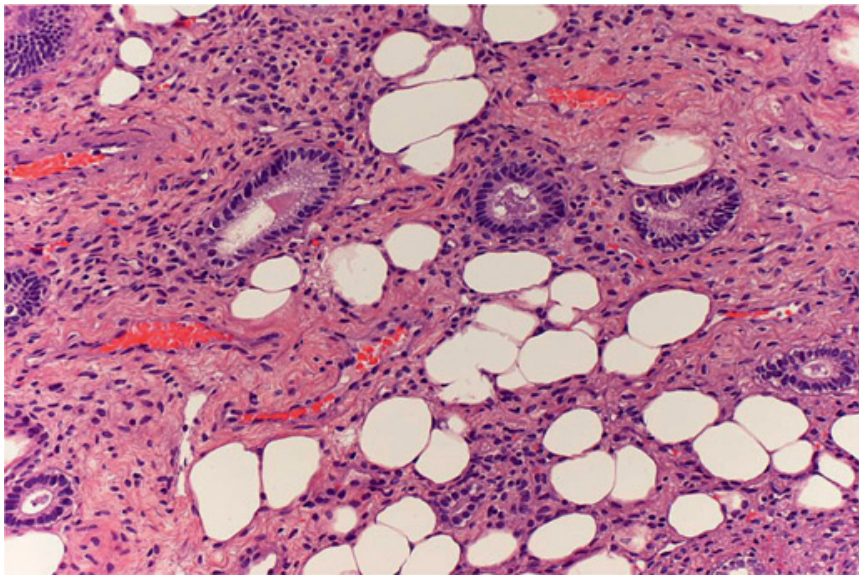

Figure 16 Adipose metaplasia in the stroma of an endometrial polyp.

a true metaplasia. This may also occur in some simple and complex hyperplasias, ${ }^{97}$ and even in well-differentiated adenocarcinomas, especially in those treated by progestogens.

Distinction from a neoplastic proliferation such as clear cell carcinoma or a secretory variant of endometrioid carcinoma is based on the absence of architectural complexity, stromal invasion, cellular pleomorphism and mitotic figures.

\section{STROMAL ENDOMETRIAL METAPLASIA}

Although most endometrial metaplasias involve the endometrial epithelium, there are rare cases of mesenchymal metaplasias that are usually incidental findings with little clinical significance.

The presence of heterotopic tissues in the normal endometrium is often explained as embedded fetal or embryonal tissue as a result of pregnancy termination. This may be the cause of unusual lesions such as glial nodules in the endometrium. ${ }^{98}$ In the absence of an organised histology of mesenchymal tissues and a history of previous obstetrical manipulation, metaplasia is the alternative to be considered.

As mentioned above, endometrial stem/progenitor cells are the most likely candidates for the development of a wide range of differentiations, including mesenchymal-type cells. Mesenchymal or stromal stem-cell-like precursors, isolated from the menstrual blood, show an in vitro multipotent capacity to induce myocyte, ${ }^{99} 100$ chondrocyte ${ }^{100} 101$ and adipocyte differentiation, ${ }^{99} 100102$ as well as osteogenic tissue. ${ }^{99} 100$ Unusual heterotopic cell types can also be differentiated. ${ }^{99}$ The multiple expressions of complex mesenchymal, epithelial and even neuroectodermal ${ }^{103}$ components are characteristic of malignant mixed Müllerian tumours.

\section{Osseous metaplasia}

Bone within the uterine cavity may have various origins. It can be a dystrophic phenomenon secondary to chronic endometritis $^{104}$ or cervical surgery, ${ }^{105}$ and it may also occur in the vicinity of adenocarcinomas. ${ }^{106}$ The metaplastic nature of this condition is proved by genetic analysis ${ }^{107}$ and morphologically by its continuity with stromal cells. It should be differentiated from in utero fetal bone retention after pregnancy termination. ${ }^{108}$ Osseous metaplasia can be deeply embedded in the uterine mucosa and may present the same contraceptive effect as an intrauterine contraceptive device. ${ }^{109} 110$

\section{Cartilaginous metaplasia}

Rare, benign appearing nodules of cartilage can be present in the endometrium. ${ }^{111}$ Transition between stromal and cartilaginous

\section{Take-home messages}

- Endometrial metaplasias and changes (EMCs) are a heterogeneous range of differentiations involving epithelium and stroma. The former are the more frequent, especially ciliated tubal and mucinous metaplasias and surface syncytial papillary change.

- Hormonal stimuli are the main inducing factor, although some metaplasias develop mutational phenomena.

- EMCs vary from reactive degenerative lesions such as eosinophilic clear cell and surface syncytial papillary change to others with a potential to associate with malignancy (morules) or have a preneoplastic potential (mucinous and tubal).

- The latter may occur in simple and complex glands and their architectural changes possibly hold the same prognostic significance as they do in endometrioid, hyperplastic lesions.

- Morules are markers of putative malignancy and their presence in an endometrial aspiration biopsy should prompt curettage in order to exclude complex glandular lesions.

- Recognition of endometrial epithelial metaplasias is necessary in daily diagnostic practice and should be included in the histopathological report especially when they have complex architectural features.

cells is helpful to identify them as metaplastic lesions. Although very rare, cartilaginous metaplasia of the uterus has been identified as a heterologous element of a metastatic metaplastic breast carcinoma and thus should be considered in the differential diagnosis of malignant mixed Müllerian tumour. ${ }^{112}$

\section{Adipose metaplasia}

Contrary to the myometrium and ovarian cortex, the endometrium rarely develops fatty tissue. Its presence has been described as a reactive phenomenon in the vicinity of endometrial tumours ${ }^{106}$ and polyps. Histologically, it appears as clusters or nodules of mature fat cells (figure 16), which blend at their periphery with the endometrial stroma, sometimes surrounded by a mild inflammatory reaction. ${ }^{113}$

\section{Smooth muscle metaplasia}

Smooth muscle cells can be identified in the endometrium as isolated short fascicles or even as well-defined nodules. The latter can be considered as an intraendometrial leiomyoma or, possibly, an extension of the surface myometrium. Myoid differentiation possibly takes place from endometrial stromal cells, exemplified by its presence in ovarian endometriosis ${ }^{114}$ where it can induce, in an extreme form, the so-called uterus-like mass. ${ }^{115}$

Small sex-cord-like structures with myoid differentiation, ${ }^{116}$ also known as plexiform tumourlets, are represented by sexcord-like trabeculae that coexpress CD56, cytokeratins and myoid markers. They originate from the stroma of eutopic and ectopic endometria including adenomyosis.

Competing interests None to declare.

Provenance and peer review Not commissioned; externally peer reviewed.

\section{REFERENCES}

. Hendrickson MR, Kempson RL. Endometrial epithelial metaplasias: proliferations frequently misdiagnosed as adenocarcinoma. Report of 89 cases and proposed classification. Am J Surg Pathol 1980;4:525-42.

2. Lauchlan SC. The secondary müllerian system revisited. Int J Gynecol Pathol 1994;13:73-9. 
3. Chan RW, Schwab KE, Gargett CE. Clonogenicity of human endometrial epithelial and stromal cells. Biol Reprod 2004;70:1738-50.

4. Schwab KE, Gargett CE. Co-expression of two perivascular cell markers isolates mesenchymal stem-like cells from human endometrium. Hum Reprod 2007;22:2903-11.

5. Dimitrov R, Timeva T, Kyurkchiev D, et al. Characterization of clonogenic stromal cells isolated from human endometrium. Reproduction 2008;135:551-8.

6. Tsuji S, Yoshimoto M, Takahashi K, et al. Side population cells contribute to the genesis of human endometrium. Fertil Steril 2008:90(4 Suppl):1528-37.

7. Taylor HS. Endometrial cells derived from donor stem cells in bone marrow transplant recipients. JAMA 2004:292:81-5

8. Maruyama T, Masuda $\mathrm{H}, \mathrm{Ono} \mathrm{M}$, et al. Human uterine stem/progenitor cells: their possible role in uterine physiology and pathology. Reproduction 2010;140:11-22

9. Carlson JW, Mutter GL. Endometrial intraepithelial neoplasia is associated with polyps and frequently has metaplastic change. Histopathology 2008;53:325-32.

10. Hejmadi RK, Chaudhri S, Ganesan R, et al. Morphologic changes in the endometrium associated with the use of the mirena coil: a retrospective study of 106 cases. Int J Surg Pathol 2007;15:148-54.

11. Mutter GL, Bergeron C, Deligdisch L, et al. The spectrum of endometrial pathology induced by progesterone receptor modulators. Mod Pathol 2008:21:591-8.

12. Fukunaga $\mathbf{M}$, Ushigome $\mathbf{S}$. Epithelial metaplastic changes in ovarian endometriosis. Mod Pathol 1998:11:784-8.

13. Clement PB. The pathology of endometriosis: a survey of the many faces of a common disease emphasizing diagnostic pitfalls and unusual and newly appreciated aspects. Adv Anat Pathol 2007;14:241-60.

14. McCluggage WG. Mullerian adenosarcoma of the female genital tract. Adv Anat Pathol 2010;17:122-9.

15. Reiter RJ. Uterine metaplasia and plasma levels of vitamin A. Anat Rec 1965;152:1-7

16. Rorat $\mathbf{E}$, Wallach RC. Papillary metaplasia of the endometrium: clinical and histopathologic considerations. Obstet Gynecol 1984:64(3 Suppl):90S-2S.

17. Andersen WA, Taylor PT Jr, Fechner RE, et al. Endometrial metaplasia associated with endometrial adenocarcinoma. Am J Obstet Gynecol 1987;157:597-604.

18. Kaku T, Tsukamoto N, Tsuruchi N, et al. Endometrial metaplasia associated with endometrial carcinoma. Obstet Gynecol 1992;80:812-16.

19. Kaku T, Silverberg SG, Tsukamoto N, et al. Association of endometrial epithelial metaplasias with endometrial carcinoma and hyperplasia in Japanese and American women. Int J Gynecol Pathol 1993;12:297-300.

20. Dane C, Tatar Z, Dane B. Clinicopathologic analysis: relationship between endometrial carcinoma and uninvolved endometrium. Eur J Gynaecol Oncol 2009;30:71-4.

21. Saegusa M, Okayasu I. Frequent nuclear beta-catenin accumulation and associated mutations in endometrioid-type endometrial and ovarian carcinomas with squamous differentiation. J Pathol 2001;194:59-67.

22. Brachtel EF, Sánchez-Estevez C, Moreno-Bueno G, et al. Distinct molecular alterations in complex endometrial hyperplasia (CEH) with and without immature squamous metaplasia (squamous morules). Am J Surg Pathol 2005;29:1322-9.

23. Chiarelli S, Buriticá C, Litta $\mathrm{P}$, et al. An immunohistochemical study of morules in endometrioid lesions of the female genital tract: CD10 is a characteristic marker of morular metaplasia. Clin Cancer Res 2006;12:4251-6.

24. Cameron RI, Maxwell P, Jenkins D, et al. Immunohistochemical staining with MIB1, bcl2 and p16 assists in the distinction of cervical glandular intraepithelial neoplasia from tubo-endometrial metaplasia, endometriosis and microglandular hyperplasia. Histopathology 2002; 41:313-21

25. Little L, Stewart CJ. Cyclin D1 immunoreactivity in normal endocervix and diagnostic value in reactive and neoplastic endocervical lesions. Mod Pathol 2010:23:611-18.

26. Fruin AH, Tighe JR. Tubal metaplasia of the endometrium. J Obstet Gynaecol Br Commonw 1967:74:93-7.

27. Hendrickson MR, Kempson RL. Ciliated carcinoma-a variant of endometrial adenocarcinoma: a report of 10 cases. Int J Gynecol Pathol 1983;2:1-12

28. Quddus MR, Sung CJ, Zheng W, et al. p53 immunoreactivity in endometrial metaplasia with dysfunctional uterine bleeding. Histopathology 1999;35:44-9.

29. Moritani S, Kushima R, Ichihara S, et al. Eosinophilic cell change of the endometrium: a possible relationship to mucinous differentiation. Mod Pathol 2005; 18:1243-8.

30. Crum CP, Nucci MR, Mutter GL. Altered endometrial differentiation (metaplasia). In: Crum CP, Lee KR, eds. Diagnostic Gynecologic and Obstetric Pathology. Philadelphia: Saunders, 2006:520-44

31. Comer MT, Shires M, Goode NP, et al. Expression of an antigen associated with basal bodies of human ciliated epithelial cells. Histochem J 1999;31:39-43.

32. Horree N, Heintz AP, Sie-Go DM, et al. p16 is consistently expressed in endometrial tubal metaplasia. Cell Oncol 2007:29:37-45.

33. Piek JMJ, Van Diest PJ, Verheijen RHM, et al. Cell cycle-related proteins p21 and bcl-2: markers of differentiation in the human fallopian tube. Histopathology 2001:38:481-2.

34. Haibach $\mathbf{H}$, Oxenhandler RW, Luger AM. Ciliated adenocarcinoma of the endometrium. Acta Obstet Gynecol Scand 1985;64:457-62.

35. Low SE, Nicol A. Ciliated cell variant of endometrioid adenocarcinoma: a rare tumour. J Clin Pathol 2004;57:1341-2.

36. Clement PB, Young RH. Florid cystic endosalpingiosis with tumor-like manifestations: a report of four cases including the first reported cases of transmural endosalpingiosis of the uterus. Am J Surg Pathol 1999;23:166-75.
37. Nucci MR, Prasad CJ, Crum CP, et al. Mucinous endometrial epithelial proliferations: a morphologic spectrum of changes with diverse clinical significance. Mod Pathol 1999:12:1137-42.

38. Schlesinger C, Kamoi S, Ascher SM, et al. Endometrial polyps: a comparison study of patients receiving tamoxifen with two control groups. Int J Gynecol Pathol 1998:17:302-11.

39. Deligdisch L, Kalir T, Cohen CJ, et al. Endometrial histopathology in 700 patients treated with tamoxifen for breast cancer. Gynecol Oncol 2000;78:181-6.

40. Honoré LH. Benign obstructive myxometra: report of a case. Am J Obstet Gynecol 1979;134:847-9.

41. Mikami Y, Kiyokawa T, Sasajima Y, et al. Reappraisal of synchronous and multifocal mucinous lesions of the female genital tract: a close association with gastric metaplasia. Histopathology 2009;54:184-91.

42. Vang R, Tavassoli FA. Proliferative mucinous lesions of the endometrium: analysis of existing criteria for diagnosing carcinoma in biopsies and curettings. Int J Surg Pathol 2003;11:261-70.

43. Anjarwalla S, Rollason TP, Rooney N, et al. Atypical mucinous metaplasia and intraepithelial neoplasia of the female genital tract-a case report and review of the literature. Int J Gynecol Cancer 2007;17:1147-50.

44. Jovanovic AS, Boynton KA, Mutter GL. Uteri of women with endometrial carcinoma contain a histopathological spectrum of monoclonal putative precancers, some with microsatellite instability. Cancer Res 1996;56:1917-21.

45. Mangili G, Taccagni G, Garavaglia E, et al. An unusual admixture of neoplastic and metaplastic lesions of the female genital tract in the Peutz-Jeghers Syndrome. Gynecol Oncol 2004:92:337-42

46. McKenney JK, Longacre TA. Low-grade endometrial adenocarcinoma: a diagnostic algorithm for distinguishing atypical endometrial hyperplasia and other benign (and malignant) mimics. Adv Anat Pathol 2009:16:1-22.

47. Baker AC, Eltoum I, Curry RO, et al. Mucinous expression in benign and neoplastic glandular lesions of the uterine cervix. Arch Pathol Lab Med 2006;130:1510-15.

48. Lehman MB, Hart WR. Simple and complex hyperplastic papillary proliferations of the endometrium: a clinicopathologic study of nine cases of apparently localized papillary lesions with fibrovascular stromal cores and epithelial metaplasia. Am J Surg Pathol 2001;25:1347-54.

49. Oiu W, Mittal K. Comparison of morphologic and immunohistochemical features of cervical microglandular hyperplasia with low-grade mucinous adenocarcinoma of the endometrium. Int J Gynecol Pathol 2003;22:261-5.

50. Zaloudek C, Hayashi GM, Ryan IP, et al. Microglandular adenocarcinoma of the endometrium: a form of mucinous adenocarcinoma that may be confused with microglandular hyperplasia of the cervix. Int J Gynecol Pathol 1997;16:52-9.

51. Wells M, Tiltman A. Intestinal metaplasia of the endometrium. Histopathology 1989;15:431-3.

52. Lauchlan SC. Metaplasias and neoplasias of Müllerian epithelium. Histopathology 1984:8:543-57.

53. Chinen K, Kamiyama K, Kinjo T, et al. Morules in endometrial carcinoma and benign endometrial lesions differ from squamous differentiation tissue and are not infected with human papillomavirus. J Clin Pathol 2004;57:918-26.

54. Makishi S, Kinjo T, Sawada S, et al. Morules and morule-like features associated with carcinomas in various organs: report with immunohistochemical and molecular studies. J Clin Pathol 2006:59:95-100.

55. Brown D Jr, Spjut HJ. Extensive squamous metaplasia of the endometrium (ichthyosis uteri). South Med J 1982;75:593-5

56. Nogales F, Parache J, Martinez H. Pathological anatomy of genital tuberculosis. Report on 1205 cases. Gynakol Rundsch 1969;7:81-101.

57. Buckley CH. Normal endometrium and non-proliferative conditions of the endometrium. In: Fox H, Wells M, eds. Haines and Taylor obstetrical and gynecological pathology. 5th edn. London: Churchill Livingstone, 2003:391-441.

58. Houghton 0, Connolly LE, McCluggage WG. Morules in endometrioid proliferations of the uterus and ovary consistently express the intestinal transcription factor CDX2 Histopathology 2008; 53:156-65.

59. Risse EK, Beerthuizen RJ, Vooijs GP. Cytologic and histologic findings in women using an IUD. Obstet Gynecol 1981; 58:569-73.

60. Hameed M, Heller DS, Murphy G. Squamous metaplasia of endometrium after uterine artery embolization for symptomatic leiomyomata. J Am Assoc Gynecol Laparosc 2002;9:70-2.

61. Baggish MS, Woodruff JD. The occurrence of squamous epithelium in the endometrium. Obstet Gynecol Surv 1967;22:69-115.

62. Miranda MC, Mazur MT. Endometrial squamous metaplasia. An unusual response to progestin therapy of hyperplasia. Arch Pathol Lab Med 1995;119:458-60.

63. Wheeler DT, Bristow RE, Kurman RJ. Histologic alterations in endometrial hyperplasia and well-differentiated carcinoma treated with progestins. Am J Surg Pathol 2007:31:988-98.

64. Murhekar K, Majhi U, Sridevi V, et al. Does "ichthyosis uteri" have malignant potential? A case report of squamous cell carcinoma of endometrium associated with extensive ichthyosis uteri. Diagn Pathol 2008;3:4

65. Stastny JF, Ben-Ezra J, Stewart JA, et al. Condyloma and cervical intraepithelial neoplasia of the endometrium. Gynecol Obstet Invest 1995;39:277-80.

66. Szczepulska E, Nasierowska-Guttmejer A, Bidziński M. Cervical verrucous carcinoma involving endometrium. Case report. Eur J Gynaecol Oncol 1999:20:35-7.

67. Kurman RJ, Norris HJ. Evaluation of criteria for distinguishing atypical endometrial hyperplasia from well-differentiated carcinoma. Cancer 1982;49:2547-59. 
68. Silverberg SG, Kurman RJ. Tumors of the uterine corpus and gestational trophoblastic disease. In: Atlas of Tumor Pathology, Third series. Washington, D.C.: Armed Forces Institute of Pathology, 1992:200-4.

69. Mayer RH. Die Pathologische Anatomie der Gebärmutter. In: Henke F, Lubarsch 0, eds. Handbuch der Speziellen Pathologischen Anatomie und Histologie. Berlin: Julius Springer, 1930:178-81.

70. Dutra FR. Intraglandular morules of the endometrium. Am J Clin Pathol 1959;31:60-5

71. Cameselle-Teijeiro J, Alberte-Lista L, Chiarelli S, et al. CD10 is a characteristic marker of tumours forming morules with biotin-rich, optically clear nuclei that occur in different organs. Histopathology 2008;52:389-92.

72. Palacios J, Catasús L, Moreno-Bueno G, et al. Beta- and gamma-catenin expression in endometrial carcinoma. Relationship with clinicopathological features and microsatellite instability. Virchows Arch 2001;438:464-9.

73. Moreno-Bueno G, Hardisson D, Prat J, et al. Nuclear beta-catenin is a molecular feature of type I endometrial carcinoma. J Pathol 2004;202:511-12.

74. Saegusa M, Hashimura M, Kuwata $T$, et al. Beta-catenin simultaneously induces activation of the p53-p21WAF1 pathway and overexpression of cyclin D1 during squamous differentiation of endometrial carcinoma cells. Am J Pathol 2004:164:1739-49.

75. Nakatani Y, Masudo K, Nozawa A, et al. Biotin-rich, optically clear nucle express estrogen receptor-beta: tumors with morules may develop under the influence of estrogen and aberrant beta-catenin expression. Hum Pathol 2004;35:869-74

76. Saegusa $\mathbf{M}$, Hashimura $\mathbf{M}$, Kuwata $T$, et al. A functional role of $\mathrm{Cdx2}$ in beta-catenin signaling during transdifferentiation in endometrial carcinomas. Carcinogenesis 2007;28:1885-92.

77. Wani Y, Notohara K, Saegusa $\mathrm{M}$, et al. Aberrant $\mathrm{Cdx} 2$ expression in endometrial lesions with squamous differentiation: important role of $\mathrm{Cdx} 2$ in squamous morula formation. Hum Pathol 2008;39:1072-9

78. Gamachi A, Kashima K, Daa T, et al. Aberrant intranuclear localization of biotin biotin-binding enzymes, and beta-catenin in pregnancy-related endometrium and morule-associated neoplastic lesions. Mod Pathol 2003;16:1124-31.

79. Lin MC, Lomo L, Baak JP, et al. Squamous morules are functionally inert elements of premalignant endometrial neoplasia. Mod Pathol 2009;22:167-74.

80. Nakatani Y, Masudo K, Miyagi Y, et al. Aberrant nuclear localization and gene mutation of beta-catenin in low-grade adenocarcinoma of fetal lung type: upregulation of the Wnt signaling pathway may be a common denominator for the development of tumors that form morules. Mod Pathol 2002;15:617-24.

81. Ueo T, Kashima K, Daa T, et al. Immunohistochemical analysis of morules in colonic neoplasms: morules are morphologically and qualitatively different from squamous metaplasia. Pathobiology 2005;72:269-78.

82. Murray SK, Clement PB, Young RH. Endometrioid carcinomas of the uterine corpus with sex cord-like formations, hyalinization, and other unusual morphologic features: a report of 31 cases of a neoplasm that may be confused with carcinosarcoma and other uterine neoplasms. Am J Surg Pathol 2005;29:157-66.

83. Abell MR. Endometrial biopsy: normal and abnormal diagnostic characteristics. In: Gold JJ, ed. Gynecologic Endocrinology. New York: Harper and Row 1975:156-90.

84. Zaman SS, Mazur MT. Endometrial papillary syncytial change: a nonspecific alteration associated with active breakdown. Am J Clin Pathol 1993;99:741-5.

85. Shah SS, Mazur MT. Endometrial eosinophilic syncytial change related to breakdown: immunohistochemical evidence suggests a regressive process. Int $\mathrm{J}$ Gynecol Pathol 2008;27:534-8

86. Jacques SM, Qureshi F, Lawrence WD. Surface epithelial changes in endometrial adenocarcinoma: diagnostic pitfalls in curettage specimens. Int J Gynecol Pathol 1995; 14:191-7

87. Nogales-Ortiz F, Puerta J, Nogales FF Jr. The normal menstrual cycle. Chronology and mechanism of endometrial desquamation. Obstet Gynecol 1978;51:259-64.

88. Gersell DJ. Endometrial papillary syncytial change. Another perspective. Am J Clin Pathol 1993:99:656-7.

89. Nicolae A, Preda 0 , Aneiros-Fernández J, et al. p16 $6^{\text {INK4A }}$ positivity identifies endometrial surface papillary syncytial change as a regressive feature associated with desquamation. Histopathology (in press).
90. Mai KT, Yazdi HM, Boone SA. 'Minimal deviation' endometrioid carcinoma with oncocytic change of the endometrium. Arch Pathol Lab Med 1995;119:751-4.

91. Silver SA, Cheung ANY, Tavassoli FA. Oncocytic metaplasia and carcinoma of the endometrium: an immunohistochemical and ultrastructural study. Int J Gynecol Pathol 1999;18:12-19.

92. Kajiwara H, Kumaki N, Hirabayashi K, et al. A case of oncocytic carcinoma of the endometrium. Arch Gynecol Obstet 2009;279:733-8.

93. Pitman MB, Young RH, Clement PB, et al. Endometrioid carcinoma of the ovary and endometrium, oxyphilic cell type: a report of nine cases. Int J Gynecol Pathol 1994;13:290-301.

94. Clement PB, Young RH. Non-endometrioid carcinomas of the uterine corpus: a review of their pathology with emphasis on recent advances and problematic aspects. Adv Anat Pathol 2004;11:117-42

95. de Otazu RD, García-Nieto L, Izaguirre-Gondra E, et al. Endometrial coccidiosis J Clin Pathol 2004:57:1104-5.

96. Stolnicu S, Preda O, Dohan M, et al. Pseudoglandular hepatoid differentiation in endometrioid carcinoma of the ovary simulates oxyphilic cell change. Int J Gynecol Pathol 2008;27:521-5.

97. Nakashima N, Nagasaka T, Murakami S, et al. Endometrial atypical hyperplasia with clear cell change spreading throughout the endometrium. Ann Diagn Pathol 2003; 7:381-6.

98. Russell P, de Costa C, Yeoh G. Fetal glial allograft in the endometrium: case report of a recurrent pseudo-tumor. Pathology 1993;25:247-9.

99. Meng X, Ichim TE, Zhong J, et al. Endometrial regenerative cells: a novel stem cell population. J Trans/ Med 2007:5:57.

100. Gargett CE, Schwab KE, Zillwood RM, et al. Isolation and culture of epithelial progenitors and mesenchymal stem cells from human endometrium. Biol Reprod 2009:80:1136-45

101. Wolff EF, Wolff AB, Hongling Du, et al. Demonstration of multipotent stem cells in the adult human endometrium by in vitro chondrogenesis. Reprod Sci 2007:14:524-33.

102. Musina RA, Belyavski AV, Tarusova OV, et al. Endometrial mesenchymal stem cells isolated from the menstrual blood. Bull Exp Biol Med 2008;145:539-43.

103. García-Galvis $\mathbf{O F}$, Stolnicu S, Muñoz E, et al. Adult extrarenal Wilms tumor of the uterus with teratoid features. Hum Pathol 2009:40:418-24.

104. Courpas AS, Morris JD, Woodruff JD. Osteoid tissue in utero. Report of 3 cases Obstet Gynecol 1964;24:636-40.

105. Bedaiwy MA, Goldberg JM, Biscotti CV. Recurrent osseous metaplasia of the cervix after loop electrosurgical excision. Obstet Gynecol 2001;98:968-70.

106. Nogales FF, Gomez-Morales M, Raymundo C, et al. Benign heterologous tissue components associated with endometrial carcinoma. Int J Gynecol Pathol 1982:1:286-91.

107. Cayuela E, Perez-Medina T, Vilanova J, et al. True osseous metaplasia of the endometrium: the bone is not from a fetus. Fertil Steril 2009;91:1293. e1-4.

108. Tyagi SP, Saxena K, Rizvi R, et al. Foetal remnants in the uterus and their relation to other uterine heterotopia. Histopathology 1979:3:339-45.

109. Onderoglu LS, Yarali H, Gultekin M, et al. Endometrial osseous metaplasia: an evolving cause of secondary infertility. Fertil Steril 2008;90:2013. e9-11.

110. Tsai MC, Arunamata A, Tristan S, et al. Endometrial osseous metaplasia mimicking retained intrauterine device: a case report. J Reprod Med 2008;53:877-80.

111. Roth E, Taylor HB. Heterotopic cartilage in the uterus. Obstet Gynecol 1966;27:838-44

112. Sinkre $\mathbf{P}$, Milchgrub S, Miller DS, et al. Uterine metastasis from a heterologous metaplastic breast carcinoma simulating a primary uterine malignancy. Gynecol Oncol 2000;77:216-18.

113. Nogales FF, Pavcovich M, Medina MT, et al. Fatty change in the endometrium. Histopathology 1992:20:362-3

114. Fukunaga M. Smooth muscle metaplasia in ovarian endometriosis. Histopathology 2000:36:348-52.

115. Liang YJ, Hao O, Wu YZ, et al. Uterus-like mass in the left broad ligament misdiagnosed as a malformation of the uterus: A case report of a rare condition and review of the literature. Fertil Steril 2010;93:1347. e13-16.

116. Nogales FF, Nicolae A, García-Galvis OF, et al. Uterine and extrauterine plexiform tumourlets are sex-cord-like tumours with myoid features. Histopathology 2009:54:497-500. 